\title{
IMPACT ASSESSMENT OF WATERSHED IN DESERT REGION
}

\author{
V Madhava Rao ${ }^{\text {a }, ~ R ~ R ~ H e r m o n ~}{ }^{\text {a }}$, P Kesava Rao a, T Phanindra Kumar ${ }^{\text {a }}$ \\ ${ }^{a}$ Centre on Geoinformatics Application in Rural Development(CGARD), National Institute of Rural Development (NIRD), \\ Ministry of Rural Development, Government of India, Hyderabad, India. 500030. \\ (madhavaraov, rrhermon, kesav.nird)@gmail.com, tphani108@yahoo.com
}

\section{Commission: VIII , WG VIII/6}

KEY WORDS: Watershed, Cartosat, LULC,Image Processing, NDVI, Change Detection

\begin{abstract}
:
Change detection from different temporal images usually based on reflectance on natural and human activity impact, using integrated GIS, Remote Sensing and image processing technologies enable impact assessment of watershed in desert region. A time series analysis of seasonal NDVI have been used to estimate net primary productivity, phonological characteristic of vegetative surface, length of growing season and dry drown periods (Ramsey et al., 1995). The study is designed to achieve the objectives to Study the changes in vegetation for selected watershed in a desert districts of Bhilwara, Barmer \& Jaisalmer in Rajastan State of India, to identify the changes in density of vegetation, to assess the temporal changes and to assess the impact of the watershed, with an objective to conserve the soil erosion and harvest the rainwater in order to increase the ground water table, to improve the socio economic condition of the people and to stop the migration of the people from the villages in search of livelihood. These activities will have a direct impact on the crop production. The Changes in density of vegetation indicates the quantity of crop production and the growth of vegetation apart from crops and the conservation of land with out scrub/barren land to land with scrub. This gives an picture about the impact of watershed programme in increasing the vegetative cover. The temporal changes help in understanding the changes taken place in the watershed, and facilitate understand the positive as well as negative impacts of any decisions taken in the implementation. The extent and density and type of vegetation for the years, 2000,2004,2005,2007 and 2008, was studied and vegetation growth was analysed using GIS and Digital Image Processing techniques.
\end{abstract}

\section{INTRODUCTION}

Till the recent past, land was looked in a narrow perspective of being a physical entity in terms of its topography and spatial nature.But the broader, integrative or holistic view, takes into account both, a vertical aspect from atmospheric climate down to ground water resources, and a horizontal aspect an identifiable repetitive sequence of soil, terrain, hydrological, vegetative and land use elements.

Watershed-based development has been the strategy for growth and sustainability of agriculture in the vast semiarid and dry subhumid regions popularly called rain-fed regions. Watershed Development Projects have been undertaken to enhance agricultural production, conserve natural resources base and ensure rural livelihood since 1980s.

Initially soil and water conservation was the primary objective of the program which attracted large public investments in the last 25 years. Subsequently, egalitarian principles of equity and enhancing rural livelihood were given prominence; more recently the principle of sustainable development with emphasis on tenets of development economics like cost of degradation of fragile land and economic ecology like valuation of ecological services have gained emphasis. Large investments have been assigned for watershed based development in the India's National Five-Year Plans since 1990s and more investments have been earmarked till 2025.
The natural resource data thus generated will be useful to conserve and manage watershed properly to achieve sustainable development particularly, in ecologically fragile areas in order to meet the living standards of the rural communities. The restoration of ecological balance and the productivity of various landbased activities, which can indirectly generate gainful employment to the rural poor, can be achieved through the effective use of this reliable decision support system. This model provides a holistic picture to enable to share the natural resources and protect them for the betterment of the watershed community. This will also help to plan the Infrastructural development needed such as connecting market with local produce. Geotechnical appraisal of all the surface water irrigation projects necessary to avoid unfavorable natural conditions will be easier to develop through participatory method.

The Geoinformatics based evaluation of watersheds implemented in the districts of Barmer, Bhilwara and Jaiselmer of Rajastan State, India have generated digital layers of scientific data from field based study, GPS coordinate data, satellite imageries, maps, legacy data etc which objectively assesses the overall impact of the watershed development programmes in the region.

The Department of Land Resources, Ministry of Rural Development (MoRD), Government of India, has assigned the GIS based evaluation using satellite imageries, in 7 blocks in 33 villages covering a total area of 13,500 ha in Barmer District, implemented under 7th phase, for about 27 watershed projects. In eight phase, 47 watershed projects 
are sanctioned, covering 7 blocks, in 46 villages, of an area sanctioned 23,500 ha. Under Haryali-II, 50 projects were sanctioned in 8 blocks of Barmer District, covering 50 villages, in about 2,500 ha. Under Haryali-II Special, sanctioned projects were 50 in all the eight blocks and spread out in about 77 villages, for an area of 25,000 ha. In the Jaiselmer district,under Haryali-II Special, the programme was implanted in 3 blocks, in 38 villages, covering 20,000 ha. In Bhilwara district, under IWDP-12th Phase, in one block, 11 villages, covering an area of 5,806 ha and under IWDP-9th Phase, in one block, covering 4,800 ha, was implemented.

The evaluation for all the villages where the watershed programmes were implemented was undertaken for GIS based evaluation by using satellite imageries and GPS based data.

The multi season satellite data was procured for the study area from the National Remote Sensing Centre (NRSC), Hyderabad for preliminary analysis. The analysis was validated with field survey of each structure and GPS coordinate data. Field photographs and legacy data was collected for augmenting the detail analysis. Extensive field surveys of the watersheds was carried on during last two weeks for validation of the satellite data for precise analysis and evaluation.

\section{OBJECTIVES OF THE STUDY}

The overall objective of the study was to develop an operational kit of remote sensing technology applicable at different levels of planning for watershed evaluation by using suitable satellite data products. The assessment of condition of vegetation is one of the indicators of environment. The quality and quantity of natural vegetative cover, biodiversity, forest fire, plant disease etc., are some of the areas of interest that are readily studies using remote sensing.

\section{STUDY AREA}

The study area consist of Thirtiy four villages Borala, Chohatan, Miyan ka tala, Krishn ka tala, Nimbla, Dhanau, poonjasaar, ghonia,Sarla,Gurmane ka tala, Harpalia, Alamsar,Tajanio ki tala,Hussain ka tala, Ambawa,Talsar, Jharpa, Bawarwal, Khrawala, Bijirad, Der bhimthal, Hiranio ka tala, Kharoder,Akal, Malyaon ki beri, Mokhawa, Bhabhare ki beri, Ogala, Bisarniya, Sauo ki beri, Ranasar kalan, Boli, Bnta, Sudhaberi. The geographic extents of the banera block is located between the geocoordinates of of $24^{\circ} 40^{\prime}$ to $25^{\circ} 35^{\prime} \mathrm{N}$, and $70^{\circ} 45^{\prime}$ to $71^{\circ}$ 45' E.

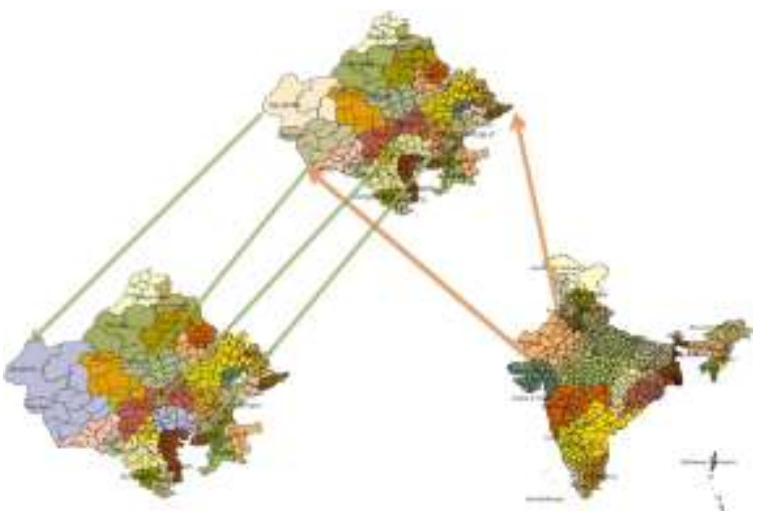

Figure-1-Study Area: Districts of Bhilwara, Barmer and Jaisalmer Rajasthan State, India

\section{METHODOLOGY}

The broad methodology adopted were digital image processing, georeferencing, subsetting, image enhancement, landuse land cover classification, supervised classification, vegetative indexes etc.

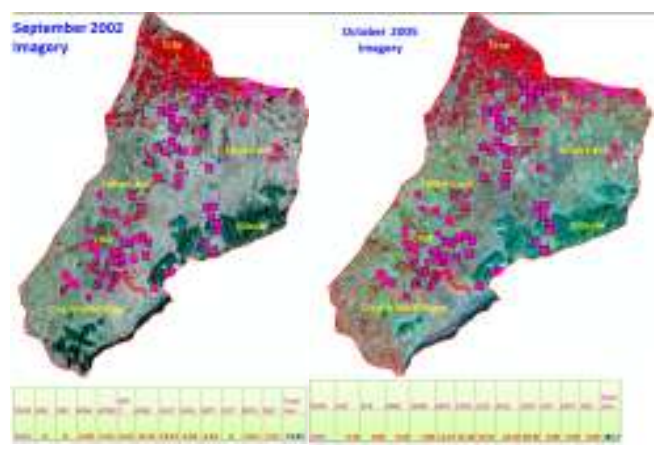

Figure-2- Change Detection between 2002 to 2005

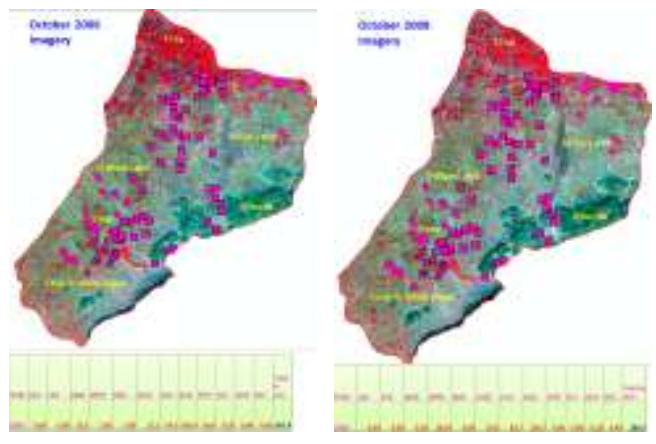

Figure-3- Change Detection between 2006 to 2008 


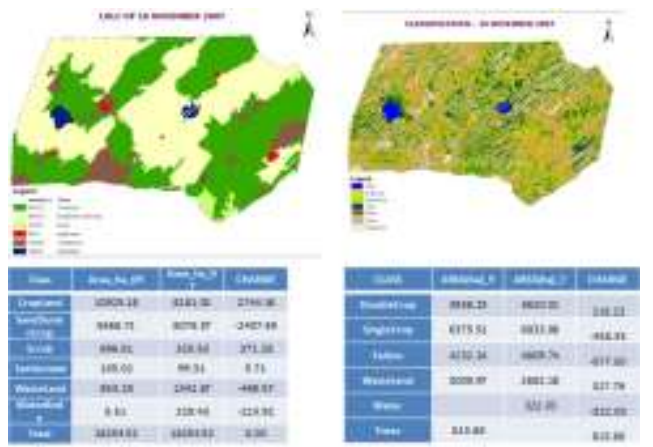

Figure-4- Change Matrix LUC between 2000 to 2005

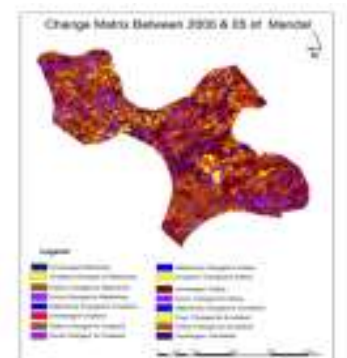

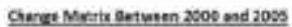

\begin{tabular}{|c|c|c|c|c|}
\hline INoxin & Wenting & Gesent & iatin & sun \\
\hline Wentibs & W & III & (ii) & 12 \\
\hline cosion & in & सम & InI & 13 \\
\hline nats & III & 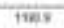 & Tws & in? \\
\hline sect & Iक & III? & 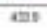 & InI \\
\hline
\end{tabular}

Figure-5- Change Matrix between 2000 to 2005

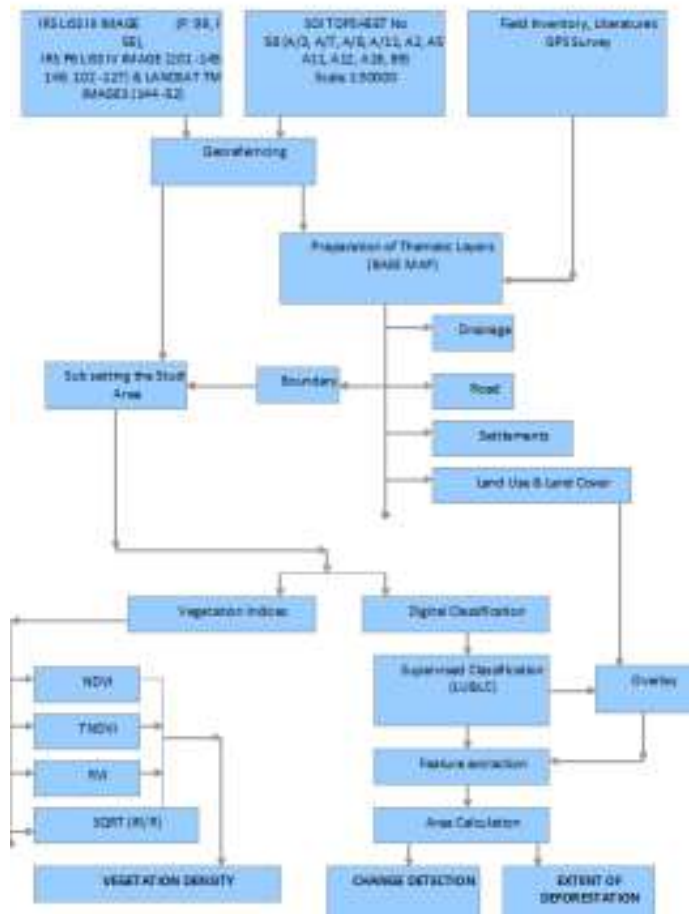

Figure-6- Methodological Flowchart
The process methodology followed is to assess the extent and density and type of vegetation and analyse the deforestation, land use and land cover, geomorphological aspects, and present land conditions, by extensive use of GIS, Remote Sensing and Digital Image Processing techniques, carried out specifically for the years, 1992, 1997, 2000, 2001, 2005 and 2007.

The Data Products Used for this study were satellite imageries, GPS/DGPD readings, Survey of India(SOI) Maps, field data from Watershed Departments to reach the implementation point and information gathered from beneficiaries and local people.

Topographic Maps. Available Topo Sheets of 1:50,000 scale were used. The satellite data products of Land sat, IRS 1C, 1D and Resourcesat P6 were used. The data was processed in GIS and Image Processing software land use and land cover maps were generated, Other techniques followed were Normalised Differential Vegetative Index(NDVI), Ratio of Vegetative Index(RVI), Square root of Vegetative Index(SQRT) and Transformed Normalised Vegetative Index(TNDI). Digital image processing was carried for the extracting information from satellite imagery by importing the image, georeferncing, subsetting study area, image enhancement, land use and land cover classification, supervised and Unsupervised classification, Accuracy Assessment, Determination of Vegetation Density, estimation of Vegetation Indices and finally estimation of Change Detection.

The following field observations were made from the watershed evaluations in the three evaluated districts:

\section{GAPS IN REMOTE SENSING FOR WATERSHED DEVELOPMENT}

User organizations like Agriculture, Rural Development, Forests and other line departments desired to use large scale maps of watershed resources to suit the village cadastral scale of $1: 7,920$ or $1: 3,960$. The resource maps at 1:25,000 scales were overlayed to reduce cadastral map at the same scale however could not satisfy the implementing agencies as many small survey numbers were left unaddressed. In addition to the resource maps, they needed a detailed contour plan of 0.30 to $0.50 \mathrm{~m}$ interval with updated cadastral boundaries to plan the layout of soil and water conservation/ harvesting structures. Another persistent demand from the said agencies is a full discovery of the remote sensing applications in different stages of planning for watershed development.

\section{AN OPTIMISTIC VIEW:}

The data requirements of the watershed agencies range from a macro to a micro level of resource information. The future missions of CARTOSAT- 1 and 2 with 2.5 and $1.0 \mathrm{~m}$ PAN resolution, respectively, and the P-6 with LISS-IV sensor resolution of $6 \mathrm{~m}$ (multispectral) and AWIFS resolution of $70 \mathrm{~m}$ imbibe a sense of optimism in meeting the objectives of watershed development agencies. The 
detailed contour information could be attempted through GPS and photogrammetric techniques.

Based on the nature of work in watershed management, a study was planned with three levels of objectives, namely, strategic, tactical and operational. The strategic objectives dealt with the characterization of macro-watersheds by computing sediment yield index through a rapid assessment of soil resources and current land use from small scale maps $(1: 250,000$ scale), followed by the determination of priority with consideration to agro-climatic and socioeconomic conditions. The tactical objectives of preparing a project plan was an inventory of land resources on subwatershed basis, using medium scale maps (1:50,000 scale). Finally the operational objectives was to fulfill through detailed inventory of land resource of a micro watershed using large scale maps $(1: 10,000$ scale $)$ to implement the program of work.

\section{RECOMMENDATIONS}

The following broad recommendations could be offered for improving the watershed development in the three districts of Rajastan for bringing visible impact on the ground:

1. From the rain fall patterns of last decade, it is observed that sudden flash floods emanated from heavy rainfall are rare and rainfall pattern is consistent or below average. Hence it is being suggested that appropriate rain water harvesting structures with requisite height should be constructed;

2. Plantation should be implemented in areas where soil condition is good and water sources are there to take care of initial months of the plantation, for their survival;

3. Too many Checkdams and Khadins should be avoided on the same drainage basin;

4. Appropriate cropping pattern suitable to the soil conditions and rainfall pattern should be promoted rather than conventional agriculture practice, which is posing nonsustainable;

5. As drinking need is very acute Tonkas need to be promoted for water storage for human and animals;

6. Development of bore wells and tube wells where ground water is not saline and water resources are available, may be considered;

7. Agro forestry for fuel wood and pasture development for fodder in suitable agri lands, needs immediate attention;

8. Stabilisation of sand dunes need to be immediately taken up in Jaiselmer and Barmer Districts;

9. Dairy has lot of promise in the region and has proved to be a good economical and livelihood support activity and needs extensive promotion;
10. Sprinkler and Drip irrigation need to be promoted wherever there is agriculture activities by ground water utilisation. Under innovative practices, additional subsidies may be considered for solar systems, biogas, sprinkler and drip irrigation etc, for integrated development of watershed;

11. Selection of watersheds should be purely on the basis of scientific basis with Block wise or District wise prioritization;

12. DPRs to be generated with Geoinformatics application or at best with the consideration of slope, aspect, drainage, land use and land cover factors;

13. For promoting scientific inputs in the watershed planning, monitoring and evaluation, value added satellite data could be procured from NRSC, Hyderabad or assistance from regional GIS Centres situated at Guwahati, Bhubaneswar, Ahmedabad and Hyderabad, in addition to the CGARD, NIRD may be approached;

14. Inventory and mapping of all existing structures before the start of work, by a GPS should be mandatory in DPR Generation, and these GPS generated GIS maps should be properly superimposed on the other base maps and satellite images as pre project scenario. At least One GPS on each block in the country is a necessity. Now hand held models of GPS are having in built cameras also. GPSs of accuracy up to 5-6 meters may be a good option for inventory and two dimensional mapping of watershed works. GPS is also available in Cell Phones now-a-days and a good precise hand held GPS could be available for Rs 50,000(US \$ $1,000)$;

15. Open source software like Quantum GIS and low priced Indigenous Software like Gram++ can be promoted at Block level and District level which are user friendly and easy to learn for having direct read, view, analyze and print capacity in native formats like shape for vector and many common raster formats;

16. As desert areas are very difficult areas for selection of proper sites for waters harvesting structures and as structures like Khadin, Dhora and Tonka(Local Traditional Water Harvesting Structures) etc consumes most of the funds, a separate per ha. cost norms for desert areas, should be considered;

17. In most of the present structures, additional deepening may cause break of base layer which causes more seepage of water to downwards which nobody knows which aquifer is going to be recharged by that water. This can in turn cause negative impact of activity;

18. Lack of Proper rates for new and innovative activities, frequent revision of rates is required: Districts in Rajasthan are having separate BSR for each district which is based on various prevailing BSR rates of forest, Irrigation and PWD etc. The rates remained constant for a longer duration than the change in the market rates of material. BSR rates should be revised and changed frequently keeping the pace with materials market. 
Absence of this encourages malpractices and false record maintenance, to fit the vouchers in the estimated labour and material cost;

19. Region specific standardization of items in estimate preparation, namely how much rows of a seed or grass are require for per running meter length? How much vegetation is required on which type of structure? Which ratio proportion concrete or masonry is appropriate for what type of WHS or building structures? For a particular type of activity how many items or things can be included in the estimates? The Agencies like KVKs, forest, Irrigation, PWD departments, CAZRI, AFRI can help in development of region specific standards for a particular activity.

This standardization of estimate preparation can be published as manual which can work as base to prepare estimates;

20. GPS entries along with Khasara no. etc. should be mandatory: In new common guidelines a huge scope is there for use of IT and GIS. It is suggested to use the GPS for entries in the measurement books, and generated shape files can be superimposed time to time on the existing various layers of various watersheds at Block level. One high end system can be earmarked at block level for this job with proper data security. By this action, time to time update of record of work execution is possible and will work as permanent asset record. At the time of exit protocol, this database can be used with pre project existing structures database to show both pre and post activities clearly;

21. Selection of local influential persons as WC Chairmen has been observed to have taken works surrounding their own farms and people may not be able to speak against these persons because scheme is for five years and people live in the same village and want to avoid clashes;

22. Plantation activity is observed to be not successful in desert areas executed by Watershed Department and post project management is also under the hand of Gram panchayats which again is not being followed by any agency, and after the utilisation of all WDF funds, no fund is there for sustaining the watershed development works. In case of Plantation Works, these should be handled by the Forest Department, as the Department of specific Staff and expertise and post project maintenance;

23. Timing of plantation and species selection in consonance with weather cycles in case of plantation improves the survival rate and sustainability.

\section{CONCLUSION}

The natural resource data thus generated will be useful to conserve and manage watershed properly to achieve sustainable development particularly, in ecologically fragile areas in order to meet the living standards of the rural communities. The restoration of ecological balance and the productivity of various land based activities, which can indirectly generate gainful employment to the rural poor, can be achieved through the effective use of this reliable decision support system.

This model provides a holistic picture to enable to share the natural resources and protect them for the betterment of then watershed community. This will also help to plan the Infrastructural development needed such as connecting market with local produce.

Geo-technical appraisal of all the surface water irrigation projects necessary to avoid unfavorable natural conditions will be easier to develop through participatory method.

\section{REFERENCES}

1. National Remote Sensing Centre Satellite Data (2005-2011), Hyderabad, India.

2. District Watershed Department DPR Reports, Bhilwara,

Barmer \& Jaisalmar Districts, Rajastan State, India.

3. Survey of India, Dehradun, India.

4. State Remote Sensing Application Centre, Jodhpur, Rajastan State, India.

5. Zilla Parishad Watershed Progress Reports, Bhilwara, Barmer \& Jaisalmar Districts, Rajastan State, India. 